\title{
Statistical visualization of the Earth's magnetotail and the implied mechanism of substorm triggering based on superposed-epoch analysis of THEMIS data
}

\author{
S. Machida ${ }^{1}$, Y. Miyashita ${ }^{1}$, A. Ieda ${ }^{1}$, M. Nosé ${ }^{2}$, V. Angelopoulos ${ }^{3}$, and J. P. McFadden ${ }^{4}$ \\ ${ }^{1}$ Solar Terrestrial Environment Laboratory, Nagoya University, Aichi, Japan \\ ${ }^{2}$ World Data Center for Geomagnetism, Kyoto University, Kyoto, Japan \\ ${ }^{3}$ Institute of Geophysics and Planetary Physics/Department of Earth, Planetary and Space Sciences, \\ University of California, Los Angeles, CA, USA \\ ${ }^{4}$ Space Sciences Laboratory, University of California, Berkeley, CA, USA \\ Correspondence to: S. Machida (machida@stelab.nagoya-u.ac.jp)
}

Received: 2 September 2013 - Revised: 5 December 2013 - Accepted: 3 January 2014 - Published: 17 February 2014

\begin{abstract}
To investigate the physical mechanism responsible for substorm triggering, we performed a superposed-epoch analysis using plasma and magnetic-field data from THEMIS probes. Substorm onset timing was determined based on auroral breakups detected by all-sky imagers at the THEMIS ground-based observatories. We found earthward flows associated with north-south auroral streamers during the substorm growth phase. At around $X=-12$ Earth radii $\left(R_{\mathrm{E}}\right)$, the northward magnetic field and its elevation angle decreased markedly approximately 4 min before substorm onset. Moreover, a northward magnetic-field increase associated with pre-onset earthward flows was found at around $X=$ $-17 R_{\mathrm{E}}$. This variation indicates that local dipolarization occurs. Interestingly, in the region earthwards of $X=-18 R_{\mathrm{E}}$, earthward flows in the central plasma sheet (CPS) reduced significantly approximately $3 \mathrm{~min}$ before substorm onset, which was followed by a weakening of dawn-/duskward plasma-sheet boundary-layer flows (subject to a $1 \mathrm{~min}$ time lag). Subsequently, approximately $1 \mathrm{~min}$ before substorm onset, earthward flows in the CPS were enhanced again and at the onset, tailward flows started at around $X=-20 R_{\mathrm{E}}$. Following substorm onset, an increase in the northward magnetic field caused by dipolarization was found in the nearEarth region. Synthesizing these results, we confirm our previous results based on GEOTAIL data, which implied that significant variations start earlier than both current disruption and magnetic reconnection, at approximately $4 \mathrm{~min}$ before substorm onset roughly halfway between the two regions of interest; i.e. in the catapult current sheet.
\end{abstract}

Keywords. Magnetospheric physics (magnetotail; storms and substorms) - space plasma physics (magnetic reconnection)

\section{Introduction}

Substorms are phenomena which take energy from the solar wind, store it as a form of magnetic-field energy, and then release that stored energy over a short time interval, triggered by some mechanism. During a substorm, field-aligned currents above the polar ionosphere intensify and auroral activity is enhanced. Associated with these variations, auroral electro-jet currents are intensified, resulting in heating of both the plasma and neutrals in the polar ionosphere. Meanwhile, current disruption (CD) and magnetic-field dipolarization occur in the night-side magnetosphere at a distance of approximately 10 Earth radii $\left(R_{\mathrm{E}}\right.$; defined with respect to the centre of the Earth). In addition, fast plasma flows associated with southward-directed magnetic fields (known as "plasmoids") are formed in the magnetotail beyond $\sim 30 R_{\mathrm{E}}$. In this manner, substorms play an important role in stabilizing the Earth's magnetosphere by releasing its excess energy. The processes characterizing substorms are related to one another, and various aspects of substorms have been studied since their discovery (e.g. Akasofu, 1964; Russell and McPherron, 1973; Nishida, 1978). In addition, many models have been proposed to explain their properties, such as the near-Earth neutral-line (NENL) model (Hones, 1976; 
Baker et al., 1996), the CD model (Chao et al., 1977; Lui et al., 1990; Lui, 1996), the thermal-catastrophe model (Smith et al., 1986), the boundary-layer model (Rostoker and Eastman, 1987), the magnetosphere-ionosphere (M-I)-coupling model (Kan et al., 1988), the ballooning-instability model (Roux et al., 1991; Cheng and Lui, 1998), the field-line resonance (FLR) model (Samson et al., 1992), the plasma-sheet divergence model (Lyons et al., 2003) and the near-Earth transition-region (NETR) model (Haerendel, 2010), among others. However, most arguments related to substorm triggering focus on whether they start from about $8 R_{\mathrm{E}}$ downtail, as predicted by the CD model, or from $\sim 20 R_{\mathrm{E}}$ earthwards, as predicted by the NENL model. Thus far, no consensus has been reached.

In this context, Nishimura et al. (2010) reported that a specific sequence of events determines substorm onsets; i.e. they are initiated by a poleward boundary intensification (PBI) and flow through north-south arced motion equatorwards ("N-S streamers"), towards the quiet arc at the onset's latitude. This suggests the importance of earthward transport of new plasma during a substorm's onset. Recently, these authors also reported that the earthward plasma flows which are associated with $\mathrm{N}-\mathrm{S}$ streamers must originate from the distant neutral line (DNL) rather than the NENL, based on observations with the ARTEMIS probe in conjunction with auroral observations using the THEMIS ground-based all-sky imager (ASI) array. They suggested that the NENL is not related to either pre-onset flow or auroral activity, but that it becomes active during the expansion phase (Nishimura et al., 2013).

Meanwhile, our superposed-epoch analyses of GEOTAIL data have shown that magnetic reconnection and dipolarization in the near-Earth magnetotail occur simultaneously (within a 2-minute time interval, which is equivalent to our time resolution) with auroral breakup, and we also found the variations commonly regarded as precursors to substorm onset halfway between the NENL and the dipolarization region. Guided by this result, we proposed a new mechanism of substorm triggering: the catapult (slingshot) current-sheet relaxation model (Machida et al., 2009). In this model, the DC Poynting flux towards the central plasma sheet (CPS) is enhanced during the substorm's growth phase. Approximately $4 \mathrm{~min}$ before its onset, the catapult current sheet relaxes, causing earthward plasma flows which accompany low-frequency electromagnetic waves just prior to substorm onset. The catapult current sheet couples strongly with the near-Earth region, producing large perturbations that initiate current disruption and magnetic-field dipolarization. At the same time, the tailward edge of the catapult current sheet becomes very thin, so that a magnetic neutral line, specifically the NENL, forms and magnetic reconnection starts. The most important feature of this model is that the cause of substorm triggering is located halfway between the $\mathrm{CD}$ regions and the NENL.
In the present study, we perform a superposed-epoch analysis using THEMIS data to further confirm the validity of various substorm triggering models, including our own model.

\section{Method of analysis}

Several of our previous studies (Machida et al., 1999; Miyashita et al., 1999, 2000, 2003, 2009) focused on structural changes in the $X-Y$ plane (i.e. the equatorial projection of the near-Earth magnetotail) during substorms; others focused on structural changes in the meridional $X-Z$ plane (Machida et al., 2000, 2009). The method used in our previous studies has the advantage that it enables us to investigate both temporal and spatial variations in various parameters based on a minimum number of assumptions, and that it offers a perspective view of substorms. Here we focus on both the structure in the $X-Z$ plane and temporal evolution in the equatorial plane using data from the five THEMIS probes (Angelopoulos et al., 2008a) to perform a superposed-epoch analysis. Magnetic-field data and plasma-moment data obtained with the Flux Gate Magnetometer (FGM) (Auster et al., 2008), Electrostatic Analyzer (ESA) and Solid State Telescope (SST) (McFadden et al., 2008) instruments onboard the THEMIS probes (each with $3 \mathrm{~s}$ time resolution) are used. Using these data is advantageous in the sense that the THEMIS probes explore the magnetosphere inside $10 R_{\mathrm{E}}$, where $\mathrm{CD}$ and dipolarization occur, and significant auroral activity is mapped onto that region. In addition, the use of simultaneous observations from five probes increases the data volume. To further improve the reliability of our superposed-epoch analysis, we used the auroral substorm onset list prepared by Nishimura et al. (2010), who obtained substorm onset times from auroral breakups, and the THEMIS ASI data with its remarkably short singleframe time resolution, typically $3 \mathrm{~s}$. Our analysis covers the period from November 2007 to April 2009, which includes both the period investigated by Nishimura et al. (2010) and also an extended period publicly accessible on the Web at http://www.atmos.ucla.edu/ toshi/files/paper/Toshi_ THEMIS_GBO_list_distribution.xls. Those events which were preceded by pseudo-breakups, as well as those comprising multiple onsets, were kept, but we selected only the first substorm onset for our analysis in these cases. Events accompanied by clear N-S streamers and those without clear N-S streamers were both contained as was done by Nishimura et al. (2010). However, they found that streamers are commonly seen several minutes prior to auroral substorm onset.

We selected data from the intervals when each THEMIS probe was located individually in the region defined by $-7.5>X\left(R_{\mathrm{E}}\right)>-23$ and $-2.5<Y\left(R_{\mathrm{E}}\right)<7.5$, where $X$ and $Y$ are the probe's location in Geocentric Solar Magnetospheric (GSM) coordinates. We collated these data in columns with $1 R_{\mathrm{E}}$ width in the $X$ direction in the region 


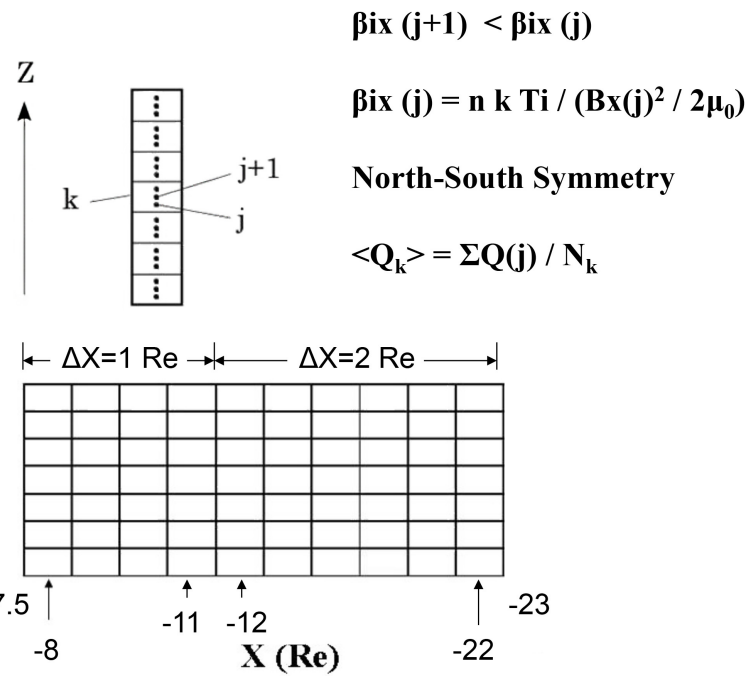

Fig. 1. Schematic illustration of our method of obtaining structures in the meridional $(X-Z)$ plane.

earthwards of $-11.5 R_{\mathrm{E}}$, just like we did with the GEOTAIL data (Machida et al., 2000). Beyond $X=-11.5 R_{\mathrm{E}}$, we set the column width to $2 R_{\mathrm{E}}$, so as to adjust for the limited number of THEMIS observations on the tailward side (see Fig. 1). A total of 642 events were analysed; we assigned multiplicity orders of $N$ when the data from $N$ different probes were used for a given event. (The net number of substorms detected was 195.) We assigned the data to the appropriate column depending on the $X$ coordinate of each probe. The numbers of events assigned to each column were $43,74,111,201$, $122,19,24,35,6$ and 7 for the columns centred at $-8,-9$, $-10,-11,-12,-14,-16,-18,-20$ and $-22 R_{\mathrm{E}}$, respectively. Next, we sorted the data into $3 \mathrm{~s}$ resolution units for every $1 \mathrm{~min}$ (i.e. one event is composed of 20 data points), assuming that events with larger $\beta_{i_{X}}=n k T_{i} /\left(B_{X}^{2} / 2 \mu_{0}\right)$ values were located closer to the plasma sheet's centre. Here, $n$, $T_{i}, B_{X}, k$ and $\mu_{0}$ are the plasma density, the ion temperature, the $X$ component of the magnetic field, Boltzmann's constant and the magnetic permeability of free space, respectively.

We separated each column into seven bins to homogenize the number of data points in each bin. We subsequently evaluated the physical parameters in each bin by averaging the $3 \mathrm{~s}$ resolution data, such as the ion number density, temperature and velocity vector, as well as the magnetic-field vector, over 1 min intervals. An advantage of this method, compared with that in which $\beta_{i_{X}}$ is taken as the ordinate, is that it provides information regarding the scale length (thickness) in the $Z$ direction. (The probability of detecting a particular structure is approximately proportional to its thickness.) We show the distribution of $\beta_{i_{X}}$ in the $X-Z$ (proxy) plane in Fig. 2a and that of $\beta_{i}=n k T_{i} /\left(B^{2} / 2 \mu_{0}\right)$ for the three components of the magnetic field in Fig. $2 b$, for reference. The inclinations of the five THEMIS probes were $7.0^{\circ}$ for $\mathrm{P} 1$ and $\mathrm{P} 2$, $9.0^{\circ}$ for $\mathrm{P} 3$ and $\mathrm{P} 4$, and $4.5^{\circ}$ for $\mathrm{P} 5$; they are distributed around an inclination of $7.5^{\circ}$, the value of the GEOTAIL inclination. The apogees are 31.6, 19.8, 12.1, 12.1 and $10.0 R_{\mathrm{E}}$ for THEMIS P1 through P5, respectively, and all THEMIS probes have perigees in the range between $1.1 R_{\mathrm{E}}$ and $1.4 R_{\mathrm{E}}$. In contrast, the GEOTAIL apogee is $30.0 R_{\mathrm{E}}$ and its perigee is $10.0 R_{\mathrm{E}}$. According to the model of Tsyganenko and Fairfield (2004), the approximate upper $Z$ limit scanned by the THEMIS probes is $6 R_{\mathrm{E}}$, which is almost the same as that pertaining to the GEOTAIL data.

\section{Results}

\subsection{Temporal evolution of the meridional structure}

Figure $3 \mathrm{a}$ shows the northward magnetic field $B_{Z}$ in the $X-Z$ (proxy) plane. The contribution from the Earth's dipole magnetic field is significant on the earthward side of $X \sim-12 R_{\mathrm{E}}$. Beyond $X \sim-12 R_{\mathrm{E}}$, a $B_{Z} \sim 0$ region is present on the side of the lobe. The nonzero $B_{Z}$ field extends from the inner dipole magnetic field to $X \sim-20 R_{\mathrm{E}}$. Near $X \sim-14 R_{\mathrm{E}}, B_{Z}$ becomes smaller than in both its earth- and tailward neighbours in the CPS. Figure $3 b$ shows the elevation angle of the local magnetic-field vector $\theta=\operatorname{atan}\left[B_{Z} / \operatorname{sqrt}\left(B_{X}^{2}+B_{Y}^{2}\right)\right]$, which has similar characteristics to those of the northward magnetic field, $B_{Z}$. The earthward side of $X \sim-12 R_{\mathrm{E}}$ is affected by a large contribution from the Earth's dipole magnetic field, to which a relatively thin layer of nonzero $\theta$ (corresponding to the thin plasma sheet) is added. The tailward boundary of this layer approaches Earth until $t=-3 \mathrm{~min}$ and the layer is thin around $X=-14 R_{\mathrm{E}}$, reflecting the small $B_{Z}$ field in that region. The $B_{Z}$ values are very small beyond $X \sim-20 R_{\mathrm{E}}$ (not shown). The thickness of the nonzero $\theta$ layer in the region $-12>X\left(R_{\mathrm{E}}\right)>-20$ seems to become smaller until $t=0$, causing magnetic-field stretching.

Figure $3 \mathrm{c}$ shows the plasma pressure, $P_{\text {th }}$ (i.e. the sum of the ion thermal pressure measured by ESA and SST) and the electron thermal pressure measured by ESA. Inside $X \sim-12 R_{\mathrm{E}}$, the plasma sheet is thick. In the vicinity of $X=-14 R_{\mathrm{E}}$, there is a gap similar to $B_{Z}$ and $\theta$. The other high-pressure area covers the region from $X \sim-15 R_{\mathrm{E}}$ to $X$ $\sim-19 R_{\mathrm{E}}$.

Figure $4 \mathrm{a}-\mathrm{c}$ shows the time evolution of $\Delta B_{Z}, \Delta \theta$ and $\Delta P_{t}$; i.e. the deviations of the northward magnetic field, the elevation angle and the total pressure (i.e. the sum of the plasma pressure and the magnetic pressure), respectively, using average values $(t=-12 \mathrm{~min}$ to $t=-10 \mathrm{~min})$. As shown in Fig. 4a, the increase caused by dipolarization starts at $t=1 \mathrm{~min}$ and progresses to a very wide area earthwards of $X=-12 R_{\mathrm{E}}$ at $t=2 \mathrm{~min}$. A small positive $\Delta B_{Z}$ region in the CPS at $X \sim-16 R_{\mathrm{E}}$ is related to the earthward flows. Negative $\Delta B_{Z}$ variations, however, appear along almost the entire boundary between the plasma sheet and lobe at $t=$ $-6 \mathrm{~min}$ and they are again noticeable at $X \sim-11 R_{\mathrm{E}}$ and 


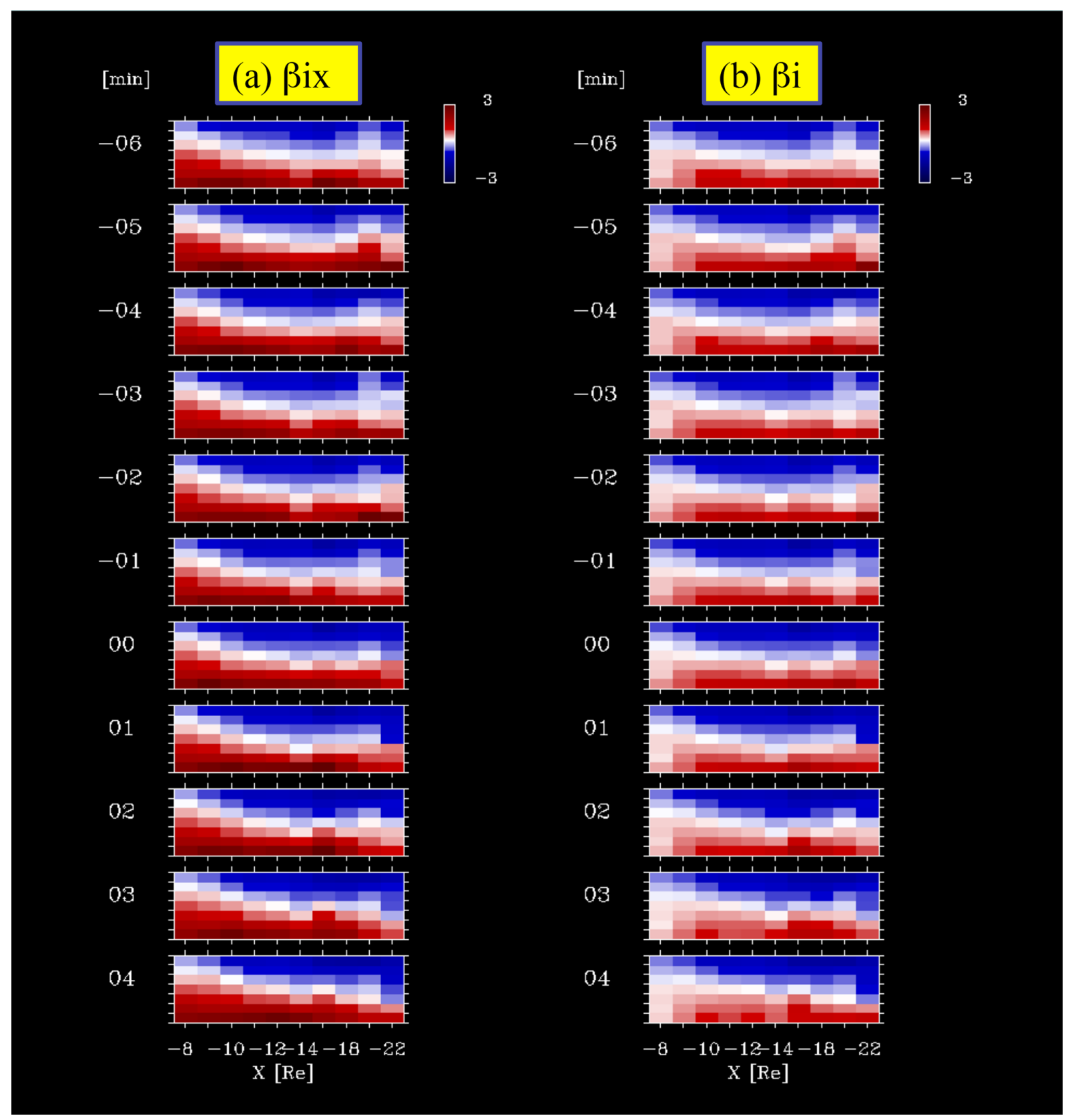

Fig. 2. Temporal evolution of (a) $\beta_{i_{X}}$ and (b) $\beta_{i}$, as defined in the text.

$X \sim-20 R_{\mathrm{E}}$. This $B_{Z}$ decrease is one of the most distinctive signatures to occur in the near-tail region. The $B_{Z}$ decrease on the earthward side seems to reflect the same variation as that recently reported by Saito et al. (2010). After substorm onset, the earthward side of this negative $\Delta B_{Z}$ variation is overcome by a positive $\Delta B_{Z}$ contribution. The variation of the elevation angle, $\Delta \theta$, is approximately proportional to $\Delta B_{Z}$. Therefore, the time evolution shown in Fig. $4 \mathrm{~b}$ is similar to that in Fig. 4a. A large increase in $\Delta \theta$ also occurs abruptly at $t=2$ min earthwards of $X=-12 R_{\mathrm{E}}$ and propagates tailwards.
The total pressure gradually increases on the side of the lobe until $t=-1 \mathrm{~min}$ at $-10>X\left(R_{\mathrm{E}}\right)>-14$, which is caused by magnetic pressure enhancement. In contrast, the total pressure decrease is caused by a plasma-pressure decrease in either the plasma sheet or the near-Earth equatorial region. After the onset, the total pressure decreases near $X=-14 R_{\mathrm{E}}$, and it increases both earth- and tailwards of that region in accordance with the recent results obtained by Miyashita et al. (2012). 


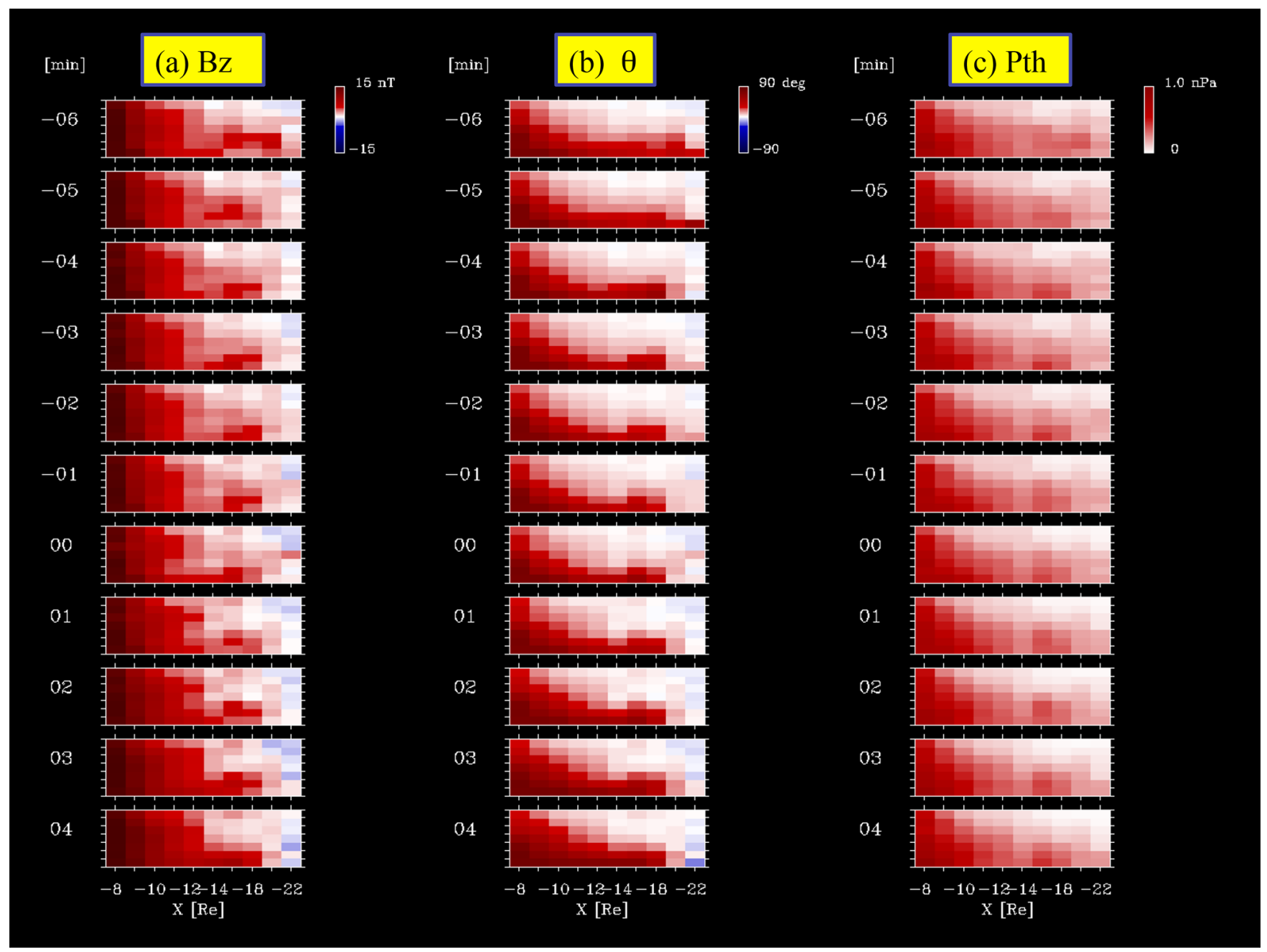

Fig. 3. Meridional structure of the magnetotail between $X=-7.5 R_{\mathrm{E}}$ and $X=-23 R_{\mathrm{E}}$. (a) Northward magnetic field, $B_{Z}$; (b) elevation angle of the magnetic field, $\theta$; and (c) thermal plasma pressure, $P_{\text {th }}$, based on ESA and SST data.

Figure 5a-c shows the ion-flow velocities, which are essentially the same as the plasma-flow velocities. Before substorm onset, both CPS flows and plasma-sheet boundarylayer (PSBL) flows are present at $X<-13 R_{\mathrm{E}}$, as reported previously (Machida et al., 2009), although the latter are not necessarily clear in the region tailwards of $X=-18 R_{\mathrm{E}}$ because of limitations inherent to the use of small-number statistics. The appearance of moderate earthward flows at $X<-13 R_{\mathrm{E}}$ prior to substorm onset is consistent with the result of a previous case study based on THEMIS data (Xing et al., 2010b). Interestingly, the CPS flows earthwards of $X=$ $-18 R_{\mathrm{E}}$ become weak between $t=-3 \mathrm{~min}$ and $t=-2 \mathrm{~min}$, and they are enhanced after $t=-1 \mathrm{~min}$. At $t=0$, tailward flows start to develop at $X \sim-20 R_{\mathrm{E}}$. In the present study, substorms of different magnitudes are selected and used in our analysis, but they are all full substorms. Therefore, this is regarded as the typical nature of full substorms. Also note that the values of the flow velocities of individual events exceed the present value, since the flow channel is relatively confined to within a narrow region, mostly in a given bin in the CPS region consisting of both flow and nonflow events, and the values shown are averages.

The absolute $V_{Y}$ value was evaluated, because the flows bifurcate at $X \sim-11 R_{\mathrm{E}}$ and both dawn- and duskward flows are present. These flows, essentially flows perpendicular to the magnetic field, are populated in the PSBL from $t=-5 \min$ to $t=1 \mathrm{~min}$ (compare Fig. 5b with Fig. 2a and b). The large $\left|V_{Y}\right|$ layer inside $X \sim-11 R_{\mathrm{E}}$ seems to be thin and becomes more distinct at $t=-2 \mathrm{~min}$. The value of $\left|V_{Y}\right|$ subsequently becomes small from $t=-2 \min$ to $t=0$ in the region earthwards of $X=-18 R_{\mathrm{E}}$, with a $\sim 1$ min time delay owing to the weakening of $V_{X}$. After the substorm onset, however, that layer spreads again. The lower trace of the large $\left|V_{Y}\right|$ layer in the pre-onset phase corresponds to the region where we found a significant reduction in both $\Delta B_{Z}$ and $\Delta \theta$. 


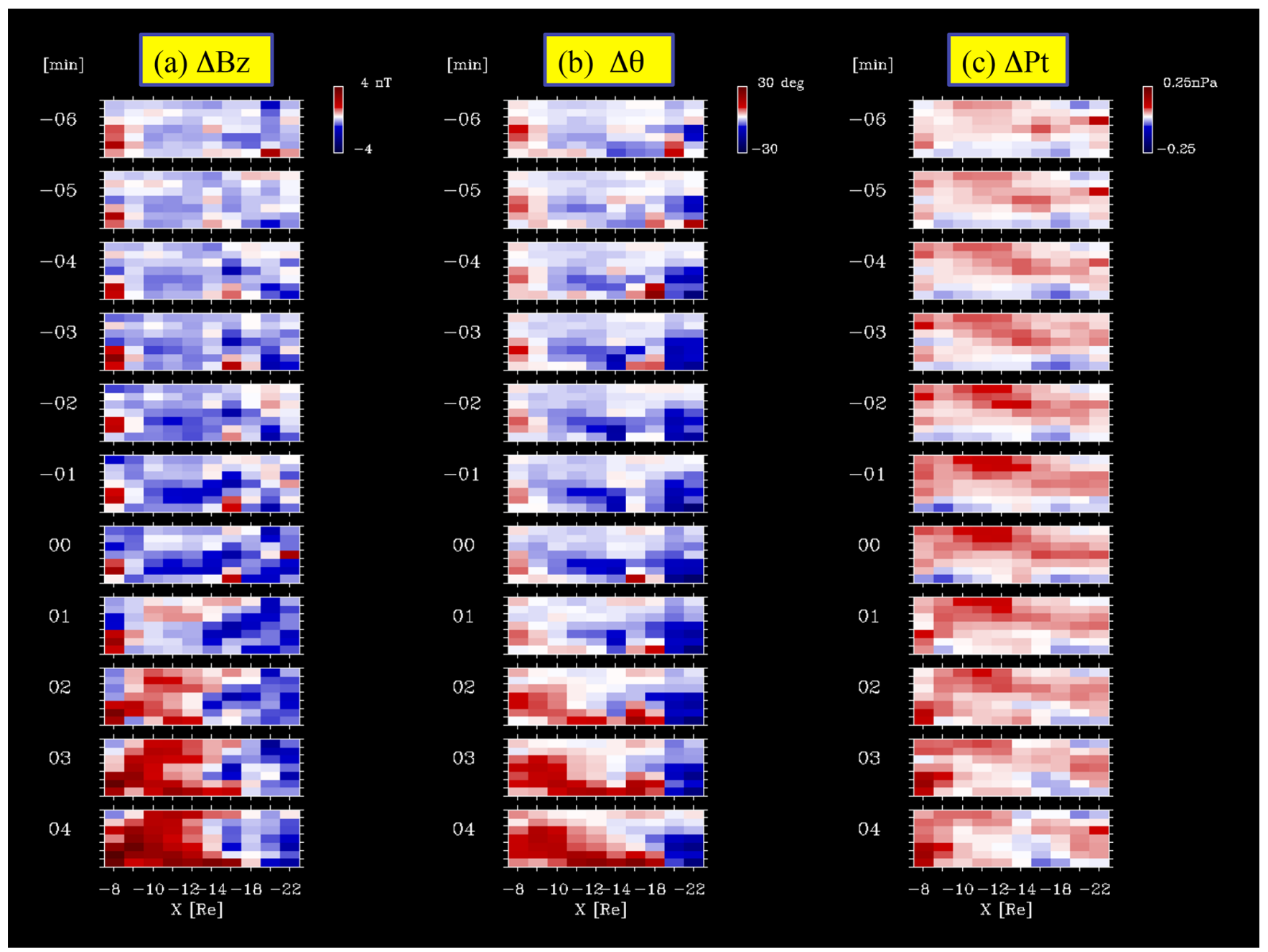

Fig. 4. Meridional displays of the deviations of (a) the northward magnetic field, $\Delta B_{Z}$; (b) the elevation angle, $\Delta \theta$; and (c) the total pressure, $\Delta P_{t}$, with respect to the relevant average values representative of the interval from $t=-12 \mathrm{~min}$ to $t=-10 \mathrm{~min}$.

The temporal evolution of $-\operatorname{sign}\left(B_{X}\right) V_{Z}$ shown in Fig. $5 \mathrm{c}$ corresponds to an enhancement of the DC Poynting flux towards the CPS. Before the substorm onset, this is caused by plasma convection during the growth phase. However, after the substorm onset, it is enhanced because of magnetic reconnection; i.e. the pronounced structure of $-\operatorname{sign}\left(B_{X}\right) V_{Z}$ corresponds to plasma inflow towards the separatrix of the magnetic-reconnection topology. Such distinctive plasma motion was also found in the case studies of Angelopoulos et al. (2008b) and Lyons et al. (2010).

\subsection{Time evolution in the equatorial region}

Figure 6a shows the time evolution of the earthward flows $V_{X}$ in the CPS region. It was constructed by selecting two bins from the bottom of each panel in Fig. 5a and evaluating average values for those bins as a function of $X$. Earthward flows (in red) at $-13>X\left(R_{\mathrm{E}}\right)>-23$ at $t=-6$ min weaken at $t=-3 \mathrm{~min}$ and $t=-2 \mathrm{~min}$. At $t=-1 \mathrm{~min}$, they start to develop at $-10>X\left(R_{\mathrm{E}}\right)>-17$. Tailward flows (in blue in Fig. 6a), which appear downtail from $X \sim-19 R_{\mathrm{E}}$ at $t=0$, are consistent with a tailward-flow study based on GEOTAIL and POLAR data (Ieda et al., 2008). If we compare this panel for $V_{X}$ with the panel for $B_{Z}$ in Fig. $7 \mathrm{a}$, we see that these tailward flows accompany a small negative $B_{Z}$ (southwardpointing) magnetic field, which indicates the occurrence of magnetic reconnection. These tailward flows grow into a well-developed plasmoid in the downtail region (e.g. Birn and Hesse, 1991; Machida et al., 1994; Ieda et al., 1998).

Figure $6 \mathrm{~b}$ shows the value of $\left|V_{Y}\right|$ at the equator. Enhancement of this parameter occurs at $X \sim-14 R_{\mathrm{E}}$ at $t=0$. There is an approximately $1 \mathrm{~min}$ time lag between the enhancement of $V_{X}$ in the vicinity of this region associated with substorm onset. The value of $\left|V_{Y}\right|$ further increases after $t=1 \mathrm{~min}$. Fast dawn- and duskward flows can be created by bifurcation of earthward flows caused by their encounter with the highpressure and dipolar magnetic-field region on the near-Earth 


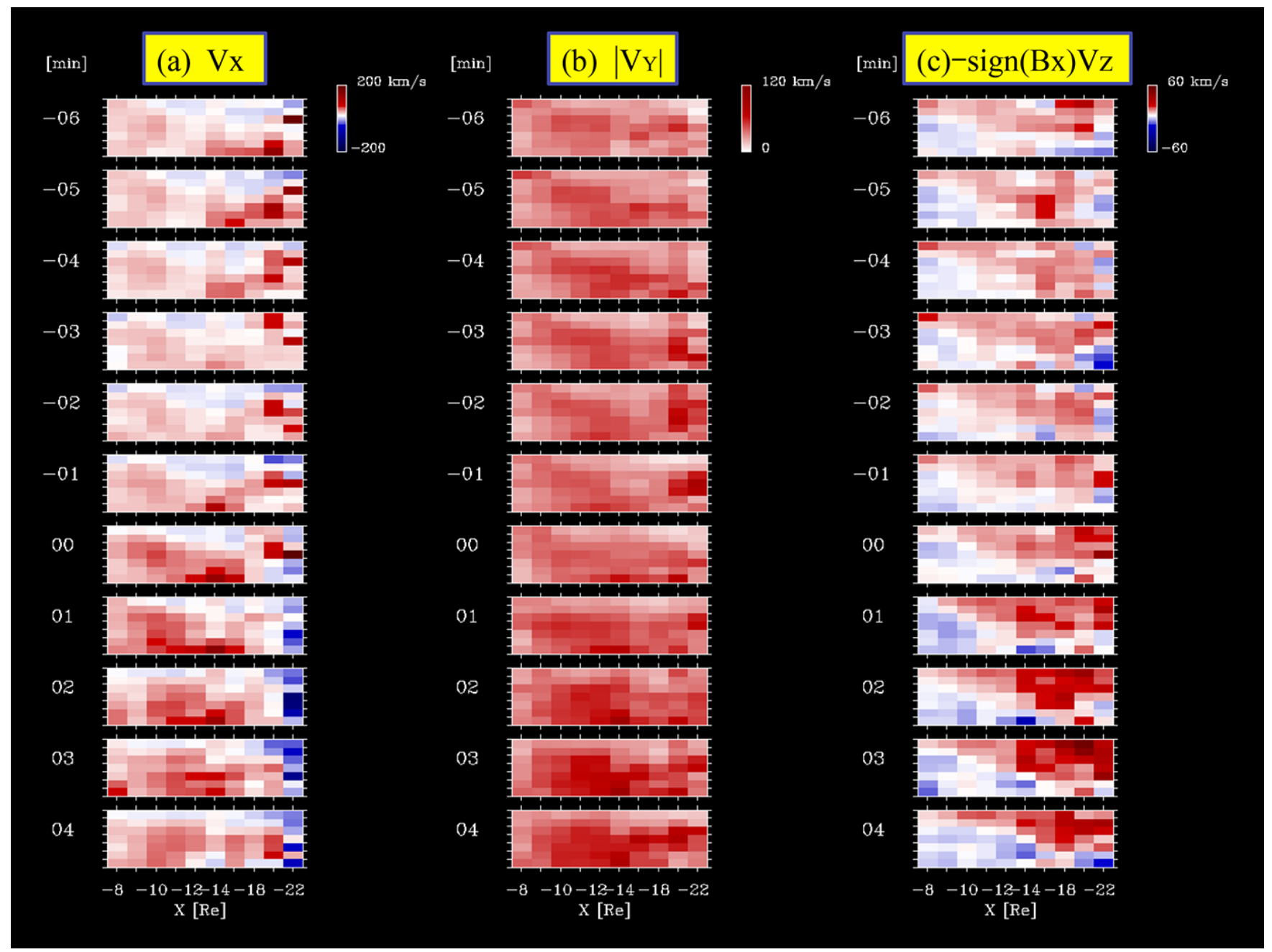

Fig. 5. Meridional displays of (a) the earthward-flow velocity, $V_{X}$; (b) the dawn-/duskward flow velocity, $\left|V_{Y}\right|$; and (c) the flow velocity towards the CPS, $-\operatorname{sign}\left(B_{X}\right) V_{Z}$.

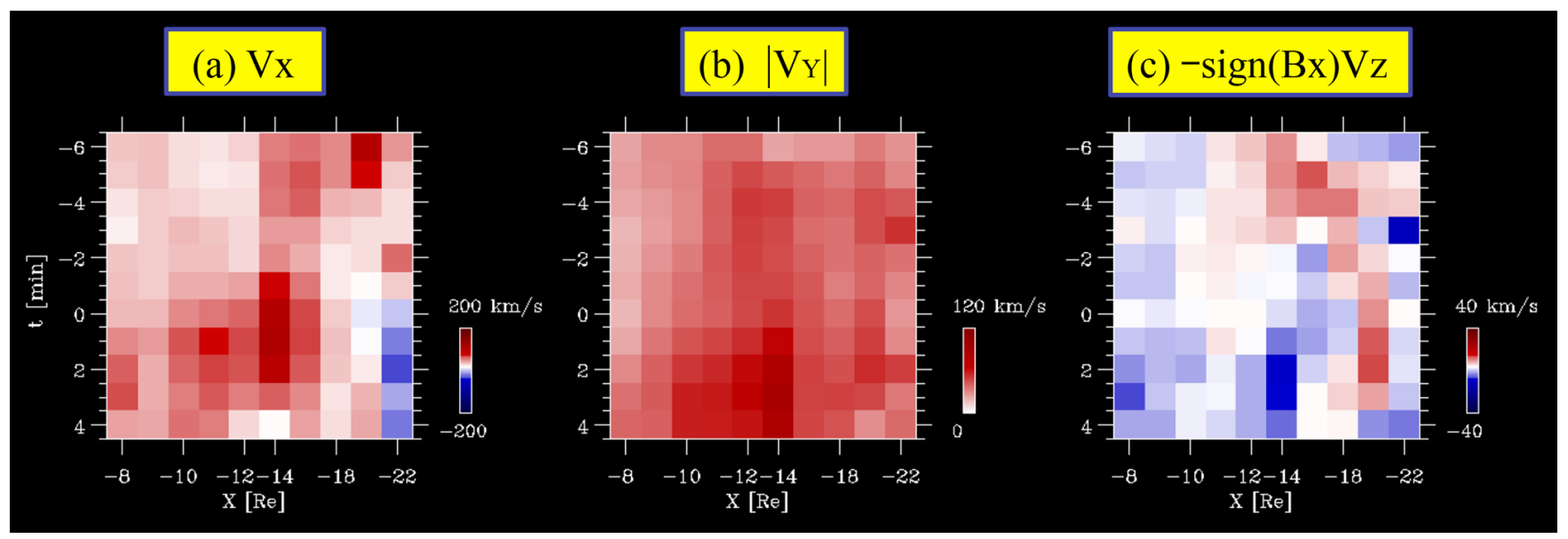

Fig. 6. Time evolution of (a) the earthward-flow velocity, $V_{X}$; (b) the dawn-/duskward flow velocity, $\left|V_{Y}\right|$; and (c) the flow velocity towards the CPS, $-\operatorname{sign}\left(B_{X}\right) V_{Z}$, in the equatorial region. 


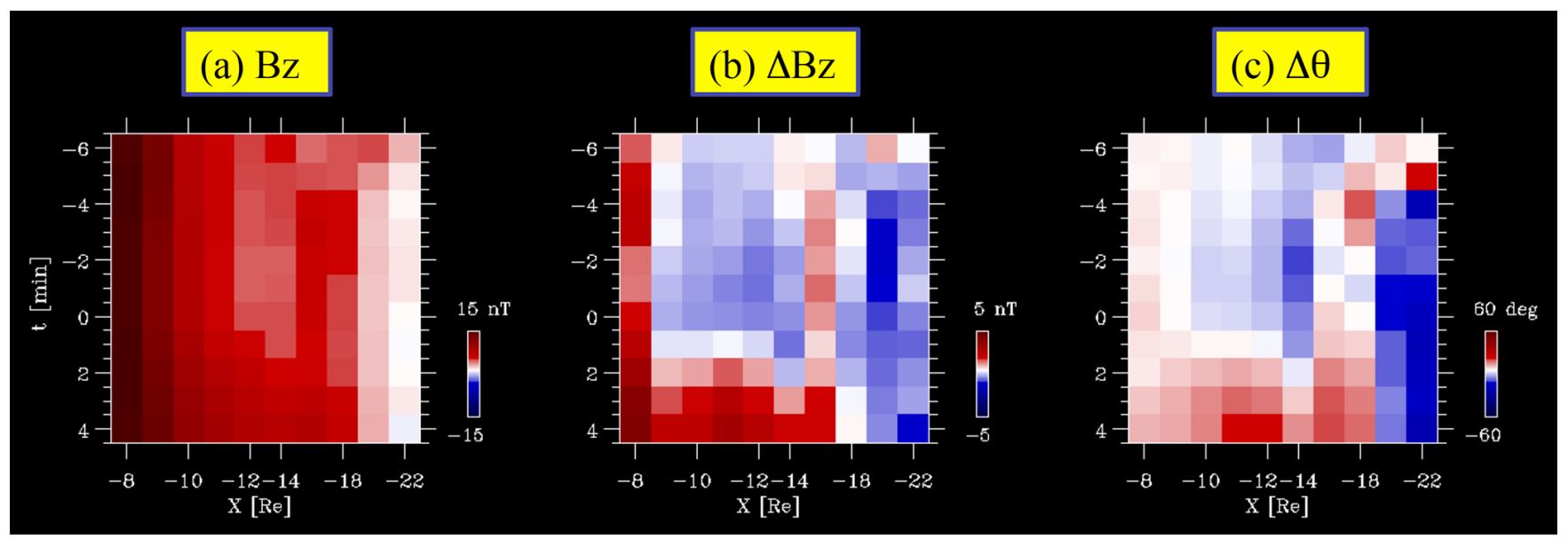

Fig. 7. As for Fig. 6, but for (a) the northward magnetic field, $B_{Z}$; (b) its deviation, $\Delta B_{Z}$; and (c) the change in elevation angle, $\Delta \theta$, in the equatorial region.

side. In the present superposed-epoch analysis, the northward magnetic-field increase owing to magnetic-flux pile-up predicted by the flow-braking model (Shiokawa et al., 1997) is not necessarily clear at this boundary. Instead, magnetic-flux pile-up can be seen before the onset around $X \sim-16 R_{\mathrm{E}}$, as we will explain below.

Similarly, flows diverging from the equator along the magnetic-field line in blue appear around $X=-14 R_{\mathrm{E}}$ after $t=1 \mathrm{~min}$ in Fig. 6c. On the other hand, convective flows towards the CPS are seen around $X=-14 R_{\mathrm{E}}$ before and subsequently at $X=-20 R_{\mathrm{E}}$ after the onset. The latter correspond to the inflow associated with magnetic reconnection.

Figure $7 \mathrm{a}$ and $\mathrm{b}$ show the time evolution of $B_{Z}$ and $\Delta B_{Z}$ at the equator, respectively. The apparent propagation of the $\Delta B_{Z}<0$ region from the earthward to the tailward side can be seen if we ignore the positive increase around $X=$ $-16 R_{\mathrm{E}}$. This variation in $\Delta B_{Z}$ is associated with plasmasheet thinning. The occurrence of such a signature has been anticipated (Akasofu, 1977; Lui et al., 1977). A significant positive $B_{Z}$ enhancement $\left(\Delta B_{Z}>0\right)$ following the onset has been attributed to dipolarization (Nagai, 1982). Another notable enhancement around $X=-16 R_{\mathrm{E}}$ at $t=-6$ min and $t=-5 \mathrm{~min}$ is caused by magnetic-flux transport and pileup associated with convective earthward flows tailwards of $X \sim-16 R_{\mathrm{E}}$ : see Fig. 5a (Baumjohann et al., 1990; Angelopoulos et al., 1992; Shiokawa et al., 1997; Slavin et al., 1997; Shue et al., 2008). It is difficult to distinguish the decrease in $B_{Z}$ beyond $X \sim-20 R_{\mathrm{E}}$ after the onset from that caused by plasma-sheet thinning. We think that it is caused by magnetic reconnection with the magnetic neutral line at $X \sim-20 R_{\mathrm{E}}$, considering the slightly negative value of $B_{Z}$ in that region and the fact that tailward flows appear in Fig. $6 \mathrm{a}$. The location of the NENL is relatively close to the Earth compared with the value obtained by Imber et al. (2011) based on the same THEMIS data. This may be attributed to the method of data selection; i.e. all travelling compression region (TCR) events were used in their study, but only the first full substorm events were used in ours. The time variation of $\Delta \theta$ shown in Fig. $7 \mathrm{c}$ is similar to that of $\Delta B_{Z}$. At two locations, $\Delta \theta$ exhibits positive values even before the onset, at $X \sim-8 R_{\mathrm{E}}$ and $X \sim-17 R_{\mathrm{E}}$. In terms of the $B_{Z}$ and $\theta$ increases, dipolarization appears to occur at $X \sim-11 R_{\mathrm{E}}$ and propagates both earth- and tailwards. The other increase in $\theta$, at $X \sim-17 R_{\mathrm{E}}$, is caused by earthward flows prior to substorm onset. Negative, positive and then negative variations in $\Delta B_{Z}$ and $\Delta \theta$ in the catapult current sheet from $X$ $\sim-13 R_{\mathrm{E}}$ to $X \sim-18 R_{\mathrm{E}}$ indicate that local dipolarization occurs around $X \sim-15 R_{\mathrm{E}}$, although the entire current sheet is stretched approximately $4 \mathrm{~min}$ before the onset. This variation is critical for our understanding of the destabilization of the catapult current sheet and, therefore, of substorm triggering.

Figure 8a shows the time evolution of the duskward electric field, $E_{Y}$, at the equator, which we evaluated using the relation $\boldsymbol{E}=-\boldsymbol{V} \times \boldsymbol{B}$. The large $E_{Y}$ region that appears at $X \sim-20 R_{\mathrm{E}}$ at $t=-6 \mathrm{~min}$ propagates earthwards, which is consistent with the results of Liu et al. (2011), who analysed the earthward-transported magnetic flux and found it to be proportional to the time integral of $E_{Y}$. As expected, regions characterized by large $E_{Y}$ correlate well with significant earthward flows.

Figure $8 \mathrm{~b}$ shows $B_{\mathrm{rms}}$ (i.e. is the root-mean-square value of the magnetic-field deviations from the average value for one spin period, $3 \mathrm{~s}$ ), which essentially represents the lowfrequency wave activity in the $0.33-16 \mathrm{~Hz}$ frequency range. This parameter exhibits a positive correlation with the earthand tailward flow velocities, $\left|V_{X}\right|$. In particular, some enhancement initially appears at $X \sim-20 R_{\mathrm{E}}$; the enhanced region subsequently shifts earthwards. An abrupt enhancement occurs at $X \sim-13 R_{\mathrm{E}}$ at $t=0$, followed by global enhancements across a wide $X$ range immediately following 


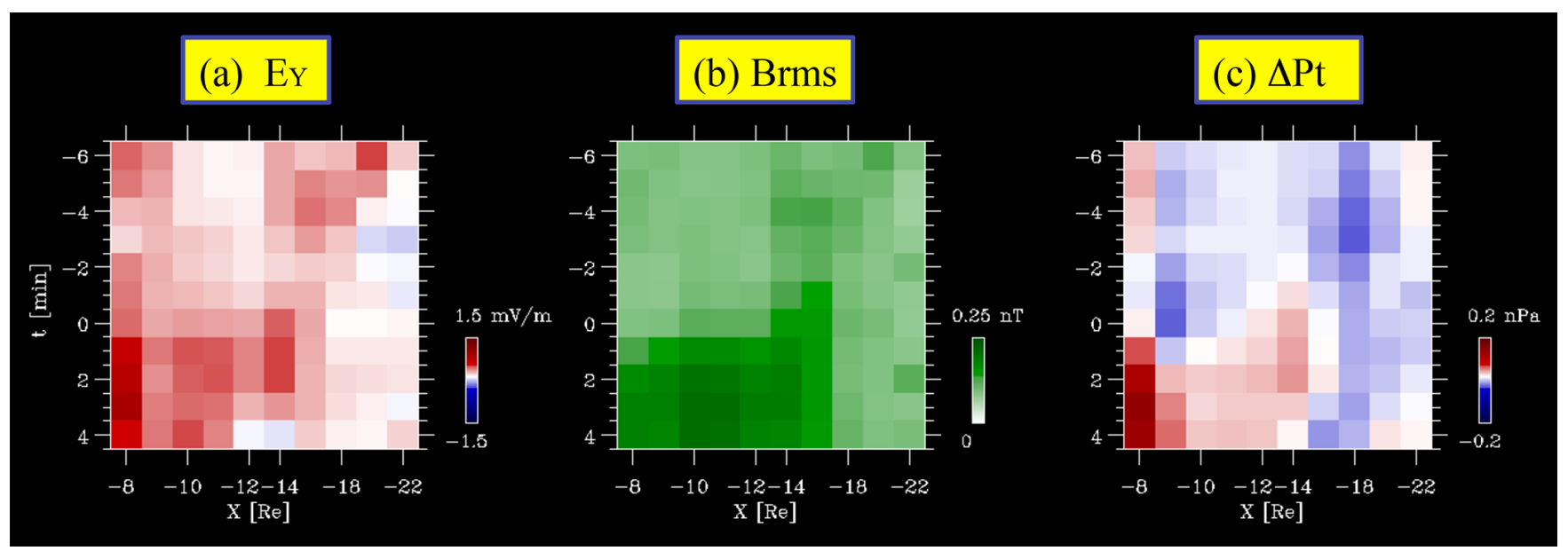

Fig. 8. As for Fig. 6, but for (a) the duskward electric field, $E_{Y}$; (b) the root-mean-square value of the magnetic field, $B_{\mathrm{rms}}$; and (c) the deviation of total pressure, $\Delta P_{t}$, in the equatorial region.

substorm onset $(t=1 \mathrm{~min})$. This parameter also correlates well with $E_{Y}$.

The deviation of the total pressure, $\Delta P_{t}$, in the equatorial region, in essence equivalent to the variation in the plasma pressure, is shown in Fig. 8c. There are two distinct regions of negative $\Delta P_{t}$, centred at $X \sim-9 R_{\mathrm{E}}$ and $X \sim-18 R_{\mathrm{E}}$. However, positive $\Delta P_{t}$ (i.e. an indication that the plasma pressure increases) occurs at $X \sim-14 R_{\mathrm{E}}$ at $t=-1 \mathrm{~min}$, which is associated with an enhancement of earthward flows. After the onset, the region of positive $\Delta P_{t}$ coincides with the region subjected to earthward flows. Earthward flows prior to substorm onset accompany the plasma-pressure decrease. It is possible that they correspond to a structure known as a plasma bubble (Pontius and Wolf, 1990; Chen and Wolf, 1993; Sergeev et al., 1996). The $P_{t}$ increase at $X \sim-8 R_{\mathrm{E}}$ after $t=1 \mathrm{~min}$ is predominantly caused by high-energy ions with energies in excess of $25 \mathrm{keV}$. Those variations are consistent with the results of recent studies (Miyashita et al., 2009; Dubyagin et al., 2010; Xing et al., 2010a).

\section{Summary and discussion}

We obtained temporal and spatial variations of the near-Earth magnetotail in the meridional plane as well as their time evolution in the equatorial plane. The results can be summarized as follows.

1. We found a minimum structure in $B_{Z}$ and $P_{\text {th }}$ at $X$ $\sim-14 R_{\mathrm{E}}$ around substorm onset.

2. Dipolarization and possibly CD start at $t=1 \mathrm{~min}$ and progress to a very wide area earthwards of $X=-12 R_{\mathrm{E}}$ at $t=2 \mathrm{~min}$.
3. Associated with plasma convection towards the CPS, the magnetic pressure is enhanced in the lobe. Following substorm onset, the total pressure decreases at $X=-14 R_{\mathrm{E}}$ and it increases both earth- and tailwards of that region.

4. Before substorm onset, both CPS and PSBL flows are present in the region at $X<-13 R_{\mathrm{E}}$. The earthward flows in the CPS, as well as the dawn-/duskward flows in the PSBL earthwards of $X=-18 R_{\mathrm{E}}$, become weak just prior to the onset. This seems to be a characteristic of full substorms.

5. Local dipolarization characterized by small positive $\Delta B_{Z}$ was found around $X=-17 R_{\mathrm{E}}$ and is associated with the earthward CPS plasma flow. This may affect the initial location of the NENL.

6. Magnetic reconnection occurs after $t=0$; its occurrence can be confirmed by the generation of tailward plasma flows with negative $B_{Z}$ and significant earthward flows with positive $B_{Z}$, as well as enhancement of the convective flows of the lobe plasma towards the CPS.

7. During the pre- and post-onset phases of a substorm, parameters such as $V_{X}, E_{Y}, B_{\mathrm{rms}}$ and $\Delta P_{t}$ show similar variations; i.e. the active region approaches the Earth. Substorms start when such active regions reach the region of $-12>X\left(R_{\mathrm{E}}\right)>-15$.

8. Following a substorm's onset, considerable variations in $V_{X}, V_{Y}, B_{Z}, E_{Y}, B_{\mathrm{rms}}$ and $P_{t}$ spread abruptly across a wide area earthwards of $X=-12 R_{\mathrm{E}}$.

Comparing the present results based on THEMIS data with our previous results from GEOTAIL (Machida et al., 2009), the locations of $B_{Z}$ reduction are different. The location of 


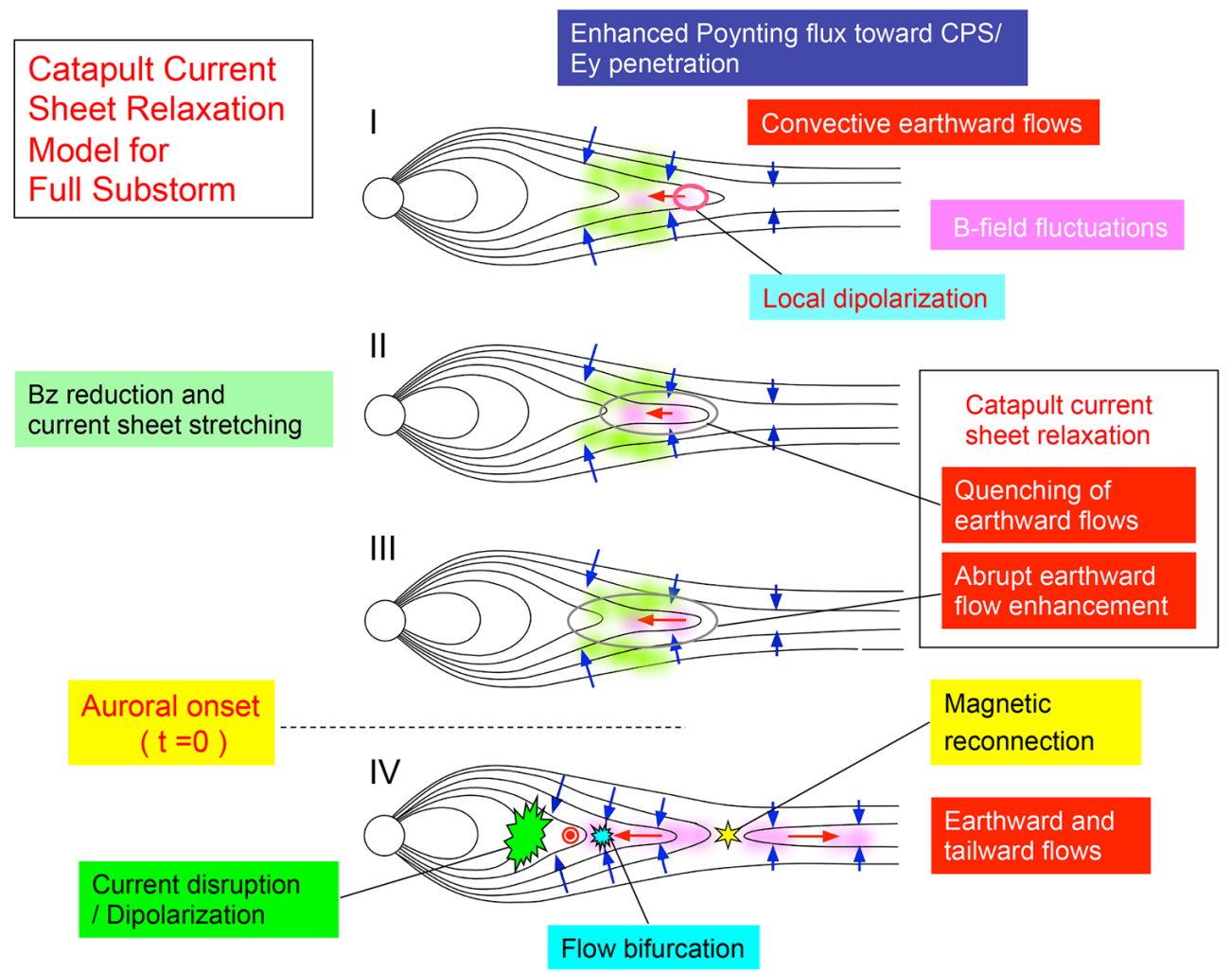

Fig. 9. Schematic illustration of the catapult current-sheet relaxation model. See the text for details.

$B_{Z}$ reduction is found at $-12>X\left(R_{\mathrm{E}}\right)>-15$ in the present study, whereas it was at $-15>X\left(R_{\mathrm{E}}\right)>-19$ in our previous study. In addition, the equatorial $B_{Z}$ peak in the midtail is located at $X \sim-19 R_{\mathrm{E}}$ only 6 min prior to the onset, whereas closer to the onset moment it shifts closer to Earth at $X \sim-16 R_{\mathrm{E}}$ in the present study. A similar earthward displacement in the peak of the earthward-flow velocity can be seen in the equatorial plane associated with that shift. In contrast, the equatorial $B_{Z}$ peak is located near $X=-20 R_{\mathrm{E}}$ at 5 min before the onset; it subsequently shifts to $X \sim-18 R_{\mathrm{E}}$ at the time of the onset. As for the plasma flow, in contrast to the GEOTAIL-based scenario in which the earthward-flow enhancement is seen at all times prior to the onset, in the THEMIS-based scenario it disappears between $t=-3 \mathrm{~min}$ and $t=-2 \mathrm{~min}$.

The time intervals covered by THEMIS in the context of the present study (November 2007 to April 2009) and by GEOTAIL analysed in our previous study (Machida et al., 2009; April 1996 to December 2002) are different. Solar activity during the corresponding periods was different. The interval covered by THEMIS corresponds to solar minimum. In contrast, the interval covered by GEOTAIL starts at solar minimum and continues to the end of solar maximum. This may cause the differences between the present THEMIS and previous GEOTAIL results.
The determination of the onset time is significant in our superposed-epoch analysis. Substorm onsets were determined based on the THEMIS ASI data in the present study. In contrast, global auroral imager data obtained with the POLAR/Ultraviolet Imager (UVI) and IMAGE/Far-Ultraviolet Imager (FUV) instruments were used in our previous study (Machida et al., 2009). The onset time $(t=0)$ corresponds to the start of the initial brightening in which a bead-like structure is formed in the auroral arc, characterized by a dramatic luminosity enhancement. The spatial resolution and optical sensitivity of the ground-based observations is higher than that of the spacecraft data, so it is possible that the onset time of the present study advances to that in our previous study. However, it is within 1-2 min, judging from the results obtained for various parameters in both cases. In addition, the different thresholds (e.g. for the luminosity of the emission or the spatial spread of the auroral breakup) used to select the substorm onset events may cause the differences between the present THEMIS and previous GEOTAIL results, in addition to the difference in solar phase. With this in mind, we can interpret the results from our THEMIS data as follows.

If a localized plasma is moving earthwards across the magnetic field in the plasma sheet, a duskward electric field will be present in that localized plasma. Electric charges accumulated at the dawn and dusk boundaries tend to be discharged by field-aligned currents and ionospheric 
conductivity between the feet of the magnetic-field lines which connect the ionosphere to the boundaries of the earthward-moving localized plasma. At the duskward boundary, the field-aligned current flows away from the ionosphere; the electrons move in the opposite direction, producing an aurora. It is possible that the N-S auroral streamer reported by Nishimura et al. (2010), as one of the key elements to understanding the triggering of substorms, corresponds to such an earthward-moving localized plasma and associated current system. Recently, Nishimura et al. (2010) confirmed that the flows associated with $\mathrm{N}-\mathrm{S}$ streamers originate from the DNL. Although we found corresponding earthward flows until $t=-4 \mathrm{~min}$, these flows became weak just a few minutes before the onset. At $t=-1 \mathrm{~min}$, earthward flows with a velocity peak in the region earthwards of $X \sim-14 R_{\mathrm{E}}$ developed. Localized tailward flows at $X \sim-20 R_{\mathrm{E}}$ start at $t=0$. Taking into account the locations of the earthward flows, we conclude that these flows are associated with relaxation of the catapult current sheet. However, they are shortly overtaken by flows produced by magnetic reconnection. The results obtained by Nishimura et al. $(2010,2013)$ for substorm triggering by new plasma intrusion originating from the DNL and those presented in this paper are complementary, and their relationship should be investigated in more detail.

Earthward flows in the CPS are thought to be convective flows that carry the magnetic flux. An increase in the northward magnetic field owing to this effect can be seen at around $X=-17 R_{\mathrm{E}}$ before substorm onset. On the other hand, a significant increase inside $X=-11 R_{\mathrm{E}}$ after the onset is caused by conventional dipolarization. Therefore, an increase in $B_{Z}$ in the catapult current-sheet region should be distinguished from equivalent increases inside $X=-11 R_{\mathrm{E}}$. Those variations in $B_{Z}$ may indicate local dipolarization in the current sheet around $X=-15 R_{\mathrm{E}}$, although the current sheet is stretched, on average.

The magnetic field associated with the earthward flows exhibits large fluctuations, as reported by Angelopoulos et al. (2002) throughout the period examined in this study. The fast flows themselves may excite large-amplitude electromagnetic waves. Since we did not analyse their frequency spectrum, we cannot determine the mode of these waves, which we therefore leave for future study. Highly structured magnetic fields in the plasma sheet may be carried by plasma flows, producing large variations at the probes' locations. Again, the formation of such highly structured magnetic fields is thought to be caused by some plasma instability.

Use of THEMIS probe data has added new information to the original GEOTAIL data, extending the boundary farther inside $10 R_{\mathrm{E}}$. We found earthward flows associated with $\mathrm{N}-\mathrm{S}$ auroral streamers, which carry the northward-directed magnetic field $B_{Z}$ and also cause a reduction in $B_{Z}$ in the lobe and the PSBL on the earthward-side, shown as Phase I in Fig. 9. Phase II is characterized by a further reduction in $B_{Z}$ at $-10>X\left(R_{\mathrm{E}}\right)>-12$ and, although the plasma sheet is stretched on average, local dipolarization occurs around $X=-15 R_{\mathrm{E}}$. At the same time, the earthward and the dawn/duskward flows weaken; the latter continue to weaken during the next phase. This phase can be regarded as an early phase of catapult current-sheet relaxation. During Phase III, from $t=-1 \mathrm{~min}$ to $t=0$, explosive catapult current-sheet relaxation occurs and a force imbalance at the earthward edge of the catapult current sheet causes a drastic structural change. Plasma instabilities, such as tearing instabilities (e.g. Sitnov and Schindler, 2010), ballooning/interchange instabilities (e.g. Pritchett and Coroniti, 2010) or kink-type instabilities (Erkaev et al., 2008) may be involved in this relaxation process. The relaxation of the catapult current sheet produces fast convective earthward flows, and this leads to considerable perturbations to the instability which already developed in the inner region. The instability thus proceeds fully nonlinearly, causing the system to develop into Phase IV, where $\mathrm{CD}$ and reconfiguration of the magnetic-field structure (i.e. dipolarization) occur. Meanwhile, the tailward edge of the catapult current sheet thins so much that the magnetic neutral line is formed and magnetic reconnection commences. Catapult current-sheet relaxation lasts for approximately $4 \mathrm{~min}$. The plasma in the region of interest is accelerated and evacuated from its earthward boundary, and the earthward flows produced by magnetic reconnection take over from the precursory flows. Once magnetic reconnection starts, it plays an important role in regulating mass and energy transport in the magnetosphere. In the same manner, $\mathrm{CD}$ causes significant variations and signatures in the inner magnetosphere and on the ground through magnetosphere-ionosphere coupling.

Acknowledgements. The authors are grateful to Y. Nishimura for providing a substorm-onset list with second timing accuracy and to K.-H. Glassmeier and H. U. Auster for THEMIS fluxgate magnetometer data. This work was supported by NASA contract NAS502099 and also by GEMSIS-I program at STEL, Nagoya university.

Topical Editor I. A. Daglis thanks L. Lyons and one anonymous referee for their help in evaluating this paper.

\section{References}

Akasofu, S.-I.: The development of the auroral substorm, Planet. Space Sci., 12, 273-282, 1964.

Akasofu, S.-I.: Physics of magnetospheric substorms (Reidel), Dordrecht, Netherlands, 1977.

Angelopoulos, V., Baumjohann W., Kennel, C. F., Coroniti, F. V., Kivelson, M. G., Pellat, R., Walker, R. J., Lühr, H., and Paschmann, G.: Bursty Bulk Flows in the Inner Central Plasma Sheet, J. Geophys. Res., 97, 4027-4039, doi:10.1029/91JA02701, 1992.

Angelopoulos, V., Chapman, J. A., Mozer, F. S., Scudder, J. D., Russell, C. T., Tsuruda, K., Mukai, T., Hughes, T. J., and Yumoto, K.: Plasma sheet electromagnetic power generation and its dissipation along auroral field lines, J. Geophys. Res., 107, 1181, doi:10.1029/2001JA900136, 2002. 
Angelopoulos, V., Sibeck, D., Carlson, C. W., McFadden, J. P., Larson, D., Lin, R. P., Bonnell, J. W., Mozer, F. S., Ergun, R., Cully, C., Glassmeier, K. H., Auster, U., Roux, A., LeContel, O., Frey, S., Phan, T., Mende, S., Frey, H., Donovan, E., Russell, C. T., Strangeway, R., Liu, J., Mann, I., Rae, J., Raeder, J., Li, X., Liu, W., Singer, H. J., Sergeev, V. A., Apatenkov, S., Parks, G., Fillingim, M., and Sigwarth, J.: First results from the THEMIS mission, Space Sci. Rev., 141, 453-476, doi:10.1007/s11214-0089378-4, 2008a.

Angelopoulos, V., McFadden, J. P., Larson, D., Carlson, C. W., Mende, S., Frey, H., Phan, T., Sibeck, D., Glassmeier, K. H., Auster, U., Donovan, E., Mann, I., Rae, J., Russell, C. T., Runov., A., Zhou, X.-Z., and Kepko, L.: Tail reconnection triggering substorm onset, Science, 321, 931-935, doi:10.1126/science.1160495, 2008b.

Auster, H. U., Glassmeier, K. H., Magnes, W., Aydogar, O., Constantinescu, D., Fischer, D., Fornacon, K. H., Georgescu, E., Harvey, P., Hillenmaier, O., Kroth, R., Ludlam, M., Narita, Y., Nakamura, R., Okrafka, K., Plaschke, F., Richter, I., Schwarzl, H., Stoll, B., Valavanoglu, A., and Wiedemann, M.: The THEMIS fluxgate magnetometer, Space Sci. Rev., 141, 235-264, doi:10.1007/s11214-008-9365-9, 2008.

Baker, D. N., Pulkkinen, T. I., Angelopoulos, V., Baumjohann, W., and McPherron, R. L.: Neutral line model of substorms: Past results and present view, J. Geophys. Res., 101, 12975-13010, doi:10.1029/95JA03753, 1996.

Baumjohann, W., Paschmann, G., and Lühr, H.: Characteristics of High-Speed Ion Flows in the Plasma Sheet, J. Geophys. Res., 95, 3801-3809, doi:10.1029/JA095iA04p03801, 1990.

Birn, J. and Hesse, M.: Substorm features in MHD simulations of magnetotail dynamics, in: Magnetospheric Substorms, Geophys. Monogra. Ser., vol. 64, edited by: Kan, J. R., Potemra, T. A., Kokubun, S., and Iijima, T., p. 177, AGU, Washington, DC, 1991.

Chao, J. K., Kan, J. R., Lui, A. T. Y., and Akasofu, S.-I.: A model for thinning of the plasma sheet, Planet. Space Sci., 25, 703-710, 1977.

Chen, C. X. and Wolf, R. A.: Interpretation of high-speed flows in the plasma sheet, J. Geophys. Res., 98, 21409-21419, doi:10.1029/93JA02080, 1993.

Cheng, C. Z. and Lui, A. T. Y.: Kinetic ballooning instability for substorm onset and current disruption observed by AMPTE/CCE, Geophys. Res. Lett., 25, 4091-4094, doi:10.1029/1998GL900093, 1998.

Dubyagin, S., Sergeev, V., Apatenkov, S., Angelopoulos, V., Nakamura, R., McFadden, J., Larson, D., and Bonnell, J.: Pressure and entropy changes in the flow-braking region during magnetic field dipolarization, J. Geophys. Res., 115, A10225, doi:10.1029/2010JA015625, 2010.

Erkaev, N. V., Semenov, V. S., and Biernat, H. K.: Magnetic double gradient mechanism for flapping oscillations of a current sheet, Geophys. Res. Lett., 35, L02111, doi:10.1029/2007GL032277, 2008.

Haerendel, G.: Equatorward moving arcs and substorm onset, J. Geophys. Res., 115, A07212, doi:10.1029/2009JA015117, 2010.

Hones Jr., E. W.: The magnetotail: Its generation and dissipation, in: Physics of Solar Planetary Environments, edited by: Williams, D. J., AGU, Washington, DC, 559-571, 1976.

Ieda, A., Machida, S., Mukai, T., Saito, Y., Yamamoto, T., Nishida, A., Terasawa, T., and Kokubun, S.: Statistical analysis of the plas- moid evolution with Geotail observations, J. Geophys. Res., 103, 4453-4465, doi:10.1029/97JA03240, 1998.

Ieda, A., Fairfield, D. H., Slavin, J. A., Liou, K. , Meng, C.-I., Machida, S., Miyashita, Y., Mukai, T., Saito, Y., Nosé, M., Shue, J.-H., Parks, G. K., and Fillingim, M. O.: Longitudinal association between magnetotail reconnection and auroral breakup based on Geotail and Polar observations, J. Geophys. Res., 113, A08207, doi:10.1029/2008JA013127, 2008.

Imber, S. M., Slavin, J. A., Auster, H. U., and Angelopoulos, V.: A THEMIS survey of flux ropes and traveling compression regions: Location of the near-Earth reconnection site during solar minimum, J. Geophys. Res., 116, A02201, doi:10.1029/2010JA016026, 2011.

Kan, J. R., Zhu, L., and Akasofu, S.-I.: A theory of substorms: Onset and subsidence, J. Geophys. Res., 93, 5624-5640, 1988.

Liu, J., Gabrielse, C., Angelopoulos, V., Frissell, N. A., Lyons, L. R., McFadden, J. P., Bonnell, J., and Glassmeier, K. H.: Superposed epoch analysis of magnetotail flux transport during substorms observed by THEMIS, J. Geophys. Res., 116, A00I29, doi:10.1029/2010JA015886, 2011.

Lui, A. T. Y.: Current disruption in the Earth's magnetosphere: Observations and models, J. Geophys. Res., 101, 13067-13088, doi:10.1029/96JA00079, 1996.

Lui, A. T. Y., Meng, C.-I., and Akasofu, S.-I.: Search for the magnetic neutral line in the near-Earth plasma sheet 2. Systematic study of Imp 6 magnetic field observations, J. Geophys. Res., 82, 1547-1565, doi:10.1029/JA082i010p01547,1977.

Lui, A. T. Y., Mankofsky, A., Chang, C.-L., Papadopoulos, K., and Wu, C. S.: A current disruption mechanism in the neutral sheet: A possible trigger for substorm expansions, Geophys. Res. Lett., 17, 745-748, doi:10.1029/GL017i006p00745, 1990.

Lyons, L. R., Wang, C.-P., and Nagai, T.: Substorm onset by plasma sheet divergence, J. Geophys. Res., 108, 1427, doi:10.1029/2003JA010178, 2003.

Lyons, L. R., Nishimura, Y., Xing, X., Angelopoulos, V., Zou, S., Larson, D., McFadden, J., Runov, A., Mende, S., and Fornacon, K.-H.: Enhanced transport across entire length of plasma sheet boundary field lines leading to substorm onset, J. Geophys. Res., 115, A00I07, doi:10.1029/2010JA015831, 2010.

Machida, S., Mukai, T., Saito, Y., Obara, T., Yamamoto, T., Nishida, A., Hirahara, M., Terasawa, T., and Kokubun, S.: GEOTAIL low energy particle and magnetic field observations of a plasmoid at $\mathrm{X}_{\mathrm{GSM}}=-142 R_{\mathrm{E}}$, Geophys. Res. Lett., 21, 2995-2998, doi:10.1029/94GL02241, 1994.

Machida, S., Miyashita, Y., Ieda, A., Nishida, A., Mukai, T., Saito, Y., and Kokubun, S.: GEOTAIL observations of flow velocity and north-south magnetic field variations in the near and middistant tail associated with substorm onsets, Geophys. Res. Lett., 26, 635-638, doi:10.1029/1999GL900030, 1999.

Machida, S., Ieda, A., Mukai, T., Saito, Y., and Nishida, A.: Statistical visualization of Earth's magnetotail during substorms by means of multidimensional superposed epoch analysis with Geotail data, J. Geophys. Res., 105, 25291-25303, doi:10.1029/2000JA900064, 2000.

Machida, S., Miyashita, Y., Ieda, A., Nosé, M., Nagata, D., Liou, K., Obara, T., Nishida, A., Saito, Y., and Mukai, T.: Statistical visualization of the Earth's magnetotail based on Geotail data and the implied substorm model, Ann. Geophys., 27, 1035-1046, doi:10.5194/angeo-27-1035-2009, 2009. 
McFadden, J. P., Carlson, C. W., Larson, D., Angelopoulos, V., Ludlam, M., Abiad, R., Elliott, B., Turin, P., and Marckwordt, M.: The THEMIS ESA plasma instrument and in-flight calibration, Space Sci. Rev., 141, 277-302, doi:10.1107/s11214-008-9440-2, 2008.

Miyashita, Y., Machida, S., Nishida, A., Mukai, T., Saito, Y., and Kokubun, S.: GEOTAIL observations of total pressure and electric field variations in the near and mid-distant tail associated with substorm onsets, Geophys. Res. Lett., 26, 639-642, doi:10.1029/1999GL900031, 1999.

Miyashita, Y., Machida, S., Mukai, T., Saito, Y., Tsuruda, K., Hayakawa, H., and Sutcliffe, P. R.: A statistical study of variations in the near and middistant magnetotail associated with substorm onsets: GEOTAIL observations, J. Geophys. Res., 105, 15913-15930, doi:10.1029/1999JA000392, 2000.

Miyashita, Y., Machida, S., Liou, K., Mukai, T., Saito, Y., Hayakawa, H., Meng, C.-I., and Parks, G. K.: Evolution of the magnetotail associated with substorm auroral breakups, J. Geophys. Res., 108, 1353, doi:10.1029/2003JA009939, 2003.

Miyashita, Y., Machida, S., Kamide, Y., Nagata, D., Liou, K. Fujimoto, M., Ieda, A., Saito, M. H., Russell, C. T., Christon, S. P., Nosé, M., Frey, H. U., Shinohara, I., Mukai, T., Saito, Y., and Hayakawa, H.: A state-of-the-art picture of substormassociated evolution of the near-Earth magnetotail obtained from superposed epoch analysis, J. Geophys. Res., 114, A01211, doi:10.1029/2008JA013225, 2009.

Miyashita, Y., Machida, S., Nosé, M., Liou, K., Saito, Y., and Paterson, W. R.: A statistical study of energy release and transport midway between the magnetic reconnection and initial dipolarization regions in the near-Earth magnetotail associated with substorm expansion onsets, J. Geophys. Res., 117, A11214, doi:10.1029/2012JA017925, 2012

Nagai, T.: Observed Magnetic Substorm Signatures at Synchronous Altitude, J. Geophys. Res., 87, 4405-4417, doi:10.1029/JA087iA06p04405, 1982.

Nishida, A.: Geomagnetic Diagnosis of the Magnetosphere (Springer, Heidelberg), 1978.

Nishimura, Y., Lyons, L., Zou, S., Angelopoulos, V., and Mende, S.: Substorm triggering by new plasma intrusion: THEMIS all-sky imager observations, J. Geophys. Res., 115, A07222, doi:10.1029/2009JA015166, 2010.

Nishimura, Y., Lyons, L. R., Xing, X., Angelopoulos, V., Donovan, E. F., Mende, S. B., Bonnell, J. W., and Auster, U.: Identifying the magnetotail source region leading to preonset poleward boundary intensifications, J. Geophys. Res. Space Phys., 118, 43354340, doi:10.1002/jgra.50407, 2013.

Pontius Jr., D. H. and Wolf, R. A.: Transient flux tubes in the terrestrial magnetosphere, Geophys. Res. Lett., 17, 49-52, doi:10.1029/GL017i001p00049, 1990.

Pritchett, P. L. and Coroniti, F. V.: A kinetic ballooning/interchange instability in the magnetotail, J. Geophys. Res., 115, A06301, doi:10.1029/2009JA014752, 2010.
Rostoker, G. and Eastman, T.: A boundary layer model for magnetospheric substorms, J. Geophys. Res., 92, 12187-12201, doi:10.1029/JA092iA11p12187, 1987.

Roux, A., Perraut, S., Robert, P., Morane, A., Pedersen, A., Korth, A., Kremser, G., Aparicio, B., Rodgers, D., and Pellinen, R.: Plasma sheet instability related to the westward traveling surge, J. Geophys. Res., 96, 17697-17714, doi:10.1029/91JA01106, 1991.

Russell, C. T. and McPherron, R. L.: The magnetotail and substorms, Space Sci. Rev. 15, 205-266, 1973.

Saito, M. H., Hau, L.-N., Hung, C.-C., Lai, Y.-T., and Chou, Y.-C.: Spatial profile of magnetic field in the near-Earth plasma sheet prior to dipolarization by THEMIS: Feature of minimum B, Geophys. Res. Lett., 37, L08106, doi:10.1029/2010GL042813, 2010.

Samson, J. C., Wallis, D. D., Hughes, T. J., Creutzberg, F., Ruohoniemi, J. M., and Greenwald, R. A.: Substorm intensifications and field line resonances in the nightside magnetosphere, J. Geophys. Res., 97, 8495-8518, doi:10.1029/91JA03156, 1992.

Sergeev, V. A., Angelopoulos, V., Gosling, J. T., Cattell, C. A., and Russell, C. T.: Detection of localized, plasma-depleted flux tubes or bubbles in the midtail plasma sheet, J. Geophys. Res., 101, 10817-10826, doi:10.1029/96JA00460, 1996.

Shiokawa, K., Baumjohann, W., and Haerendel, G.: Braking of high-speed flows in the near-Earth tail, Geophys. Res. Lett., 24, 1179-1182, doi:10.1029/97GL01062, 1997.

Shue, J.-H., Ieda, A., Lui, A. T. Y., Parks, G. K., Mukai, T., and Ohtani, S.: Two classes of earthward fast flows in the plasma sheet, J. Geophys. Res., 113, A02205, doi:10.1029/ 2007JA012456, 2008.

Sitnov, M. I. and Schindler, K.: Tearing stability of a multiscale magnetotail current sheet, Geophys. Res. Lett., 37, L08102, doi:10.1029/2010GL042961, 2010.

Slavin, J. A., Fairfield, D. H., Lepping, R. P., Szabo, A., Reiner, M.J., Kaiser, M., Owen, C. J., Phan, T., Lin, R., Kokubun, S., Mukai, T., Yamamoto, T., Singer, H. J., Romanov, S.A., Buechner, J., Iyemori, T., and Rostoker, G.: WIND, GEOTAIL, and GOES 9 observations of magnetic field dipolarization and bursty bulk flows in the near-tail, Geophys. Res. Lett., 24, 971-974, doi:10.1029/97GL00542, 1997.

Smith, R. A., Goertz, C. K., and Grossman, W.: Thermal catastrophe in the plasma sheet boundary layer, Geophys. Res. Lett., 13, 1380-1383, doi:10.1029/GL013i013p01380, 1986.

Tsyganenko, N. A. and Fairfield, D. H.: Global shape of the magnetotail current sheet as derived from Geotail and Polar data, J. Geophys. Res., 109, A03218, doi:10.1029/2003JA010062, 2004.

Xing, X., Lyons, L. R., Angelopoulos, V., Larson, D., Carlson, C., Runov, A., and Auster, U.: Plasma sheet pressure evolution related to substorms, J. Geophys. Res., 115, A01212, doi:10.1029/2009JA014315, 2010a.

Xing, X., Lyons, L., Nishimura, Y., Angelopoulos, V., Larson, D., Carlson, C., Bonnell, J., and Auster, U.: Substorm onset by new plasma intrusion: THEMIS spacecraft observations, J. Geophys. Res., 115, A10246, doi:10.1029/2010JA015528, 2010 b. 